\title{
License or entry with vertical differentiation in duopoly
}

\author{
Masahiko Hattori • Yasuhito Tanaka* \\ Faculty of Economics, Doshisha University, Kyoto, Japan
}

Received: 20 October 2015

Revised: 14 April 2016

Accepted: 26 April 2016

\begin{abstract}
We consider choice of options for a foreign innovating firm to license its technology for producing the high quality good to a domestic firm, or to enter the market of the domestic country with or without license. Under the assumption of uniform distribution about taste parameters of consumers; when cost functions are linear, if the low quality good's quality is sufficiently high, license without entry strategy is optimum; if the low quality good's quality is low, both of entry without license strategy and license without entry strategy are optimum; when cost functions are quadratic, if the high quality good's quality is high, license without entry strategy is optimum; if the high quality good's quality is low, entry with license strategy is optimum.
\end{abstract}

Keywords: license; entry; duopoly; vertical differentiation; foreign innovating firm JEL Classification Codes: D43, L13

\section{Introduction}

We examine a choice of options for a foreign innovating firm to license its technology for producing the high quality good to a firm in the domestic country without entry, or to enter the market of the domestic country, or to enter the market with license to the domestic firm. At present the domestic firm is a monopolist, and if the foreign firm enters, the market of the domestic country becomes a duopoly with or without vertical differentiation.

There are many references about technology adoption or R\&D investment in duopoly or oligopoly. Lots of researches focus on the relation between technology licensor and licensee. The difference of means of contracts which are royalties, up-front fees, the combinations of these two and auction are well discussed (Katz and Shapiro (1985), Kamien and Tauman (1986), Sen and Tauman (2007)). Kamien and Tauman (1986) shows that if the licensor does not have production capacity, fixed fee is better than royalty and it is also better for consumers. This topic

\footnotetext{
*Corresponding author. E-mail: yasuhito@mail.doshisha.ac.jp

Citation: Hattori, M. and Tanaka, Y. (2016) License or entry with vertical differentiation in duopoly, Economics and Business Letters, 5(1), 17-29.
} 
under Stackelberg oligopoly is discussed in Kabiraj (2004) when the licensor does not have production capacity, and discussed in Wang and Yang (2004) and Filippini (2005), when the licensor has production capacity. A Cournot oligopoly with fixed fee under cost asymmetry is analyzed in La Manna (1993). He shows that if technologies can be replicated perfectly, a lower-cost firm always has the incentive to transfer its technology and hence a Cournot-Nash equilibrium cannot be fully asymmetric, but there exists no non-cooperative Nash equilibrium in pure strategies.

Some other studies are worthy of mention, for example, Watanabe and Muto (2008), Boone (2001), Matsumura, Matsushima and Cato (2013), Pal (2010), Elberfeld and Nti (2004), Zhang, Mei and Zhong (2014), Hattori and Tanaka (2014) and (2015) and Rebolledo and Sandonís (2012).

In particular, Sen and Tauman (2007) compared the license system when the licensor is an outsider and that when the licensor is an incumbent firm. In this paper we consider a problem of choice of options for the innovating firm as an outsider to license its technology for producing the high quality good to the other firm, or to enter the market with or without license.

We will show that under the assumption of uniform distribution about taste parameters of consumers the results depend on the form of the cost functions. When the cost functions are linear, if the level of the low quality good is sufficiently high, license without entry is the optimum strategy for the foreign innovating firm; if the level of the low quality good is low, both of entry without license and license without entry are the optimum strategies. When the cost functions are quadratic, if the level of the high quality good is sufficiently high, license without entry is the optimum strategy; if the level of the high quality good is low, entry with license is the optimum strategy.

\section{The model}

Our model of vertical product differentiation is according to Mussa and Rosen (1978), Bonanno and Haworth (1998) and Tanaka (2001). There are two firms, Firm A and B, in two countries, respectively, Country A and B. Firm A produces the high-quality good whose quality is $k_{H}$, and Firm B produces the low-quality good whose quality is $k_{L}$, where $k_{H}>k_{L}>0 . k_{H}$ and $k_{L}$ are fixed. At present each firm operates as a monopolist in each country. Both of the highquality and low-quality goods are produced at the same cost.

In Country B there is a continuum of consumers with the same income, denoted by $y$, but different values of the taste parameter $\theta$. Each consumer buys at most one unit of the good. If a consumer with parameter $\theta$ buys one unit of a good of quality $k$ at price $p$, his utility is equal to $y-p+\theta k$. If a consumer does not buy the good, his utility is equal to his income $y$. The parameter $\theta$ is distributed according to a smooth distribution function $\rho=F(\theta)$ in the interval $0<\theta \leq 1$. $\rho$ denotes the probability that the taste parameter is smaller than or equal to $\theta$. The size of consumers is normalized as one. The inverse function of $F(\theta)$ is denoted by $G(\rho)$.

We consider the following two stage game:

(1) In the first stage Firm A decides whether it enters the market of Country B or not, and whether it sells a license to use new technology for producing the high-quality good to Firm B or not.

Firm A have three options. The first option is to enter the market of Country B without license to Firm B, the second option is to license its technology to Firm B without entry to the market of Country B, and the third option is to enter the market of Country B with license to Firm B. If Firm A enters, the market of Country B becomes a duopoly with or without vertical differentiation. If Firm A enters with license, both firms produce the 
high-quality good. If it enters without license, Firm A produces the high-quality good, and Firm B produces the low-quality good.

(2) In the second stage, when Firm A enters the market of Country B in the previous stage, two firms determine their outputs; when Firm A does not enter, only Firm B determines its output.

Firm B cannot enter the market of Country A. The markets of two countries are separated. The cost function of the high-quality and low-quality goods is $c(\cdot)$.

Let $p_{L}$ be the price of the good of quality $k_{L}$ and $p_{H}$ be the price of the good of quality $k_{H}$; and let $q_{A}$ and $q_{B}$ be the supplies of Firm A and B in the market of Country B. The supply of Firm A in Country A is ignored.

\section{Entry case}

\subsection{General model}

First suppose that Firm A enters the market of Country B without license to Firm B. Then, in the market of Country B Firm A supplies the high-quality good and Firm B supplies the lowquality good. Let $\theta_{L}$ be the value of $\theta$ for which the corresponding consumer is indifferent between buying nothing and buying the low-quality good. Then,

$$
\theta_{L}=\frac{p_{L}}{k_{L}}
$$

Let $\theta_{H}$ be the value of $\theta$ for which the corresponding consumer is indifferent between buying the low-quality good and the high-quality good. Then

$$
\theta_{H}=\frac{p_{H}-p_{L}}{k_{H}-k_{L}}
$$

We assume $0<\theta_{L}<\theta_{H}<1$. The direct demand function of the high-quality good is

$$
q_{H}=1-F\left(\frac{p_{H}-p_{L}}{k_{H}-k_{L}}\right),
$$

and the direct demand function of the low-quality good is

$$
q_{L}=F\left(\frac{p_{H}-p_{L}}{k_{H}-k_{L}}\right)-F\left(\frac{p_{L}}{k_{L}}\right) .
$$

We have $0<q_{L}<1,0<q_{H}<1$, and

$$
q_{A}=q_{H}, q_{B}=q_{L} \text {. }
$$

From equations (1) and (2) the inverse demand functions are

$$
\begin{gathered}
p_{H}=\left(k_{H}-k_{L}\right) G\left(1-q_{A}\right)+k_{L} G\left(1-q_{A}-q_{B}\right), \\
p_{L}=k_{L} G\left(1-q_{A}-q_{B}\right) .
\end{gathered}
$$

Since $G\left(1-q_{A}-q_{B}\right)<G\left(1-q_{A}\right)<1$, we have $p_{L}<k_{L}$ and $p_{H}<k_{H}$. The profits of Firm $\mathrm{A}$ and $\mathrm{B}$ are written as

$$
\begin{gathered}
\pi_{A}=\left[\left(k_{H}-k_{L}\right) G\left(1-q_{A}\right)+k_{L} G\left(1-q_{A}-q_{B}\right)\right] q_{A}-c\left(q_{A}\right), \\
\pi_{B}=k_{L} G\left(1-q_{A}-q_{B}\right) q_{B}-c\left(q_{B}\right) .
\end{gathered}
$$

The first order conditions for profit maximization of Firm A and B are 


$$
\begin{aligned}
\frac{\partial \pi_{A}}{\partial q_{A}}= & \left(k_{H}-k_{L}\right) G\left(1-q_{A}\right)+k_{L} G\left(1-q_{A}-q_{B}\right) \\
& -\left[\left(k_{H}-k_{L}\right) G^{\prime}\left(1-q_{A}\right)+k_{L} G^{\prime}\left(1-q_{A}-q_{B}\right)\right] q_{A}-c^{\prime}=0 \\
\frac{\partial \pi_{B}}{\partial q_{B}} & =k_{L} G\left(1-q_{A}-q_{B}\right)-k_{L} G^{\prime}\left(1-q_{A}-q_{B}\right) q_{B}-c^{\prime}=0 .
\end{aligned}
$$

The second order conditions are

$$
\begin{aligned}
\frac{\partial^{2} \pi_{A}}{\partial q_{A}^{2}}= & -2\left[\left(k_{H}-k_{L}\right) G^{\prime}\left(1-q_{A}\right)+k_{L} G^{\prime}\left(1-q_{A}-q_{B}\right)\right] \\
& +\left[\left(k_{H}-k_{L}\right) G^{\prime \prime}\left(1-q_{A}\right)+k_{L} G^{\prime \prime}\left(1-q_{A}-q_{B}\right)\right] q_{A}-c^{\prime \prime}<0, \\
\frac{\partial^{2} \pi_{B}}{\partial q_{B}^{2}}= & -k_{L}\left[2 G^{\prime}\left(1-q_{A}-q_{B}\right)-G^{\prime \prime}\left(1-q_{A}-q_{B}\right) q_{B}\right]-c^{\prime \prime}<0 .
\end{aligned}
$$

Denote the equilibrium values of the outputs of Firm A and B, the prices of the high-quality and low-quality goods, and the profits of the firms by $q_{A}^{e}, q_{B}^{e}, p_{H}^{e}, p_{L}^{e}, \pi_{A}^{e}$, and $\pi_{B}^{e}$.

In the following subsections, we will show that if the cost functions are linear and $k_{L}$ is small, Firm B cannot operate with non-negative profit and drops out from the market; however if $k_{L}$ is sufficiently large, it can get positive profit. On the other hand, if the cost functions are quadratic, Firm B always gets positive profit.

\subsection{Uniform distribution and linear cost function case}

Now assume that $\rho=F(\theta)$ has a uniform distribution, the (common) marginal cost is constant and there is no fixed cost. Denote the marginal cost by $c$. We assume $k_{H}>k_{L}>c$. Then, $\rho=$ $\theta, \theta=G(\rho)=\rho, F^{\prime}(\theta)=G^{\prime}(\rho)=1$ and $F^{\prime \prime}(\theta)=G^{\prime \prime}(\rho)=0$. There are the following two cases.

(1) When $k_{L}>\frac{2 c k_{H}}{k_{H}+c}\left(\right.$ or $\left.k_{H}<\frac{C k_{L}}{2 c-k_{L}}\right)$, the equilibrium values of the variables are

$$
\begin{gathered}
q_{A}^{e}=\frac{2 k_{H}-k_{L}-c}{4 k_{H}-k_{L}}, q_{B}^{e}=\frac{k_{H} k_{L}+c k_{L}-2 c k_{H}}{k_{L}\left(4 k_{H}-k_{L}\right)}, \\
p_{H}^{e}=\frac{2 k_{H}^{2}+3 c k_{H}-k_{H} k_{L}-c k_{L}}{4 k_{H}-k_{L}}, p_{L}^{e}=\frac{k_{H}\left(k_{L}+2 c\right)}{4 k_{H}-k_{L}}, \\
\pi_{A}^{e}=\frac{k_{H}\left(k_{L}-2 k_{H}+c\right)^{2}}{\left(4 k_{H}-k_{L}\right)^{2}}, \pi_{B}^{e}=\frac{\left(k_{H} k_{L}+c k_{L}-2 c k_{H}\right)^{2}}{k_{L}\left(4 k_{H}-k_{L}\right)^{2}} .
\end{gathered}
$$

(2) When $k_{L} \leq \frac{2 c k_{H}}{k_{H}+c}$ (or $\left.k_{H} \geq \frac{C k_{L}}{2 c-k_{L}}\right), q_{B}=0$ and the equilibrium values of the variables are

$$
\begin{gathered}
q_{A}^{e}=\frac{k_{H}-c}{2 k_{H}}, q_{B}^{e}=0, \\
p_{H}^{e}=\frac{k_{H}+c}{2}, p_{L}^{e}=c, \\
\pi_{A}^{e}=\frac{\left(k_{H}-c\right)^{2}}{4 k_{H}}, \pi_{B}^{e}=0 .
\end{gathered}
$$




\subsection{Uniform distribution and quadratic cost function case}

Now assume that $F(\theta)$ has a uniform distribution, the (common) cost function is quadratic. Let $q$ be an output of a firm; then the cost function is $c q^{2}$. The equilibrium values of the variables are

$$
\begin{gathered}
q_{A}^{e}=\frac{2 k_{H} k_{L}+2 c k_{H}-k_{L}^{2}}{4 k_{H} k_{L}+4 c k_{L}+4 c k_{H}+4 c^{2}-k_{L}^{2}}, \\
q_{B}^{e}=\frac{k_{L}\left(k_{H}+2 c\right)}{4 k_{H} k_{L}+4 c k_{L}+4 c k_{H}+4 c^{2}-k_{L}^{2}}, \\
p_{H}^{e}=\frac{\left(k_{H}+2 c\right)\left(2 k_{H} k_{L}-k_{L}^{2}+2 c k_{H}\right)}{4 k_{H} k_{L}+4 c k_{L}+4 c k_{H}+4 c^{2}-k_{L}^{2}}, \\
p_{L}^{e}=\frac{k_{L}\left(k_{H}+2 c\right)\left(k_{L}+2 c\right)}{4 k_{H} k_{L}+4 c k_{L}+4 c k_{H}+4 c^{2}-k_{L}^{2}}, \\
\pi_{A}^{e}=\frac{\left(k_{H}+c\right)\left(2 k_{H} k_{L}+2 c k_{H}-k_{L}^{2}\right)^{2}}{\left(4 k_{H} k_{L}+4 c k_{L}+4 c k_{H}+4 c^{2}-k_{L}^{2}\right)^{2}}, \\
\pi_{B}^{e}=\frac{k_{L}^{2}\left(k_{H}+2 c\right)^{2}\left(k_{L}+c\right)}{\left(4 k_{H} k_{L}+4 c k_{L}+4 c k_{H}+4 c^{2}-k_{L}^{2}\right)^{2}} .
\end{gathered}
$$

\section{License case}

\subsection{General model}

Next suppose that Firm A licenses its technology for producing the high-quality good to Firm $\mathrm{B}$ at a fixed license fee, and does not enter the market of Country B. Then, Firm B gives up the low quality good, and produces the high quality good as a monopolist paying the license fee. Denote the license fee by $L$. Suppose that the licensor can take all of the increase in the profit of Firm $B$ due to adoption of the new high-quality good.

Let $\theta_{H}$ be the value of $\theta$ for which the corresponding consumer is indifferent between buying nothing and buying the high-quality good. Then

$$
\theta_{H}=\frac{p_{H}}{k_{H}}
$$

The direct demand function is

$$
q_{H}=1-F\left(\frac{p_{H}}{k_{H}}\right) .
$$

$q_{H}$ denotes the supply of the good of quality $k_{H}$ in the market. We have $0<q_{H}<1$, and

$$
q_{B}=q_{H} \text {. }
$$

From equation (3) the inverse demand function is

$$
p_{H}=k_{H} G\left(1-q_{B}\right) \text {. }
$$

Since $0<G\left(1-q_{B}\right)<1$, we have $0<p_{H}<k_{H}$. The profit of Firm B is

$$
\pi_{B}=k_{H} G\left(1-q_{B}\right) q_{B}-c\left(q_{B}\right)-L .
$$

The first order condition for profit maximization of Firm $B$ is 


$$
\frac{\partial \pi_{B}}{\partial q_{B}}=k_{H} G\left(1-q_{B}\right)-k_{H} G^{\prime}\left(1-q_{B}\right) q_{B}-c^{\prime}=0 .
$$

The second order condition is

$$
\frac{\partial^{2} \pi_{B}}{\partial q_{B}^{2}}=-k_{H}\left[2 G^{\prime}\left(1-q_{B}\right)-G^{\prime \prime}\left(1-q_{B}\right) q_{B}\right]-c^{\prime \prime}<0 .
$$

Denote the equilibrium values of the output of Firm B, the price and its profit by $q_{B}^{l}, p_{H}^{l}$ and $\pi_{B}^{l}$

If the negotiation between the foreign firm and the domestic firm about the license fee breaks down, the foreign firm can enter the market of Country B without license. Therefore, the domestic firm must pay the difference between its profit excluding the license fee and its profit in the previous entry case. Thus, the license fee is equal to

$$
\left(\pi_{B}^{l}+L\right)-\pi_{B}^{e} \text {. }
$$

Denote it by $L^{l}$.

\subsection{Uniform distribution and linear cost function case}

In the uniform distribution and linear cost function case the equilibrium values of the variables are

$$
\begin{gathered}
q_{B}^{l}=\frac{k_{H}-c}{2 k_{H}}, p_{H}^{l}=\frac{k_{H}+c}{2}, \\
\pi_{B}^{l}=\frac{\left(k_{H}-c\right)^{2}}{4 k_{H}}-L^{l} .
\end{gathered}
$$

About the license fee there are the following two cases.

(1) When $k_{L}>\frac{2 c k_{H}}{k_{H}+c}\left(\right.$ or $\left.k_{H}<\frac{C k_{L}}{2 c-k_{L}}\right)$,

where

$$
L^{l}=\frac{A}{4 k_{H} k_{L}\left(4 k_{H}-k_{L}\right)^{2}},
$$

$$
\begin{aligned}
A= & k_{H}^{2} k_{L}^{3}-2 c k_{H} k_{L}^{3}+c^{2} k_{L}^{3}-12 k_{H}^{3} k_{L}^{2}+8 c k_{H}^{2} k_{L}^{2}-12 c^{2} k_{H} k_{L}^{2}+16 k_{H}^{4} k_{L} \\
& -16 c k_{H}^{3} k_{L}+32 c^{2} k_{H}^{2} k_{L}-16 c^{2} k_{H}^{3} .
\end{aligned}
$$

(2) When $k_{L} \leq \frac{2 c k_{H}}{k_{H}+c}$ (or $\left.k_{H} \geq \frac{C k_{L}}{2 c-k_{L}}\right)$, since $\pi_{B}^{e}=0$,

$$
L^{l}=\frac{\left(k_{H}-c\right)^{2}}{4 k_{H}} \text {. }
$$

\subsection{Uniform distribution and quadratic cost function case}

In the uniform distribution and quadratic cost function case the equilibrium values of the variables are

$$
\begin{gathered}
q_{B}^{l}=\frac{k_{H}}{2\left(k_{H}+c\right)}, p_{H}^{l}=\frac{k_{H}\left(k_{H}+2 c\right)}{2\left(k_{H}+c\right)}, \\
\pi_{B}^{l}=\frac{k_{H}^{2}}{4\left(k_{H}+c\right)}-L^{l}
\end{gathered}
$$


where

$$
L=\frac{B}{4\left(k_{H}+c\right)\left(k_{L}^{2}-4 k_{H} k_{L}-4 c k_{L}-4 c k_{H}-4 c^{2}\right)^{2}},
$$

$$
\begin{aligned}
B= & k_{H}^{2} k_{L}^{4}-12 k_{H}^{3} k_{L}^{3}-28 c k_{H}^{2} k_{L}^{3}-32 c^{2} k_{H} k_{L}^{3}-16 c^{3} k_{L}^{3}+16 k_{H}^{4} k_{L}^{2} \\
& +20 c k_{H}^{3} k_{L}^{2}-12 c^{2} k_{H}^{2} k_{L}^{2}-32 c^{3} k_{H} k_{L}^{2}-16 c^{4} k_{L}^{2}+32 c k_{H}^{4} k_{L}+64 c^{2} k_{H}^{3} k_{L} \\
& +32 c^{3} k_{H}^{2} k_{L}+16 c^{2} k_{H}^{4}+32 c^{3} k_{H}^{3}+16 c^{4} k_{H}^{2} .
\end{aligned}
$$

\section{Entry with license case}

\subsection{General model}

Suppose that Firm A enters the market of Country B and at the same time licenses its technology for producing the high-quality good to Firm B at a fixed license fee. Then, Firm B gives up the low quality good, and produces the high quality good paying the license fee. Denote the license fee by $L$. Suppose that the licensor can take all of the increase in the profit of Firm B due to adoption of the new high-quality good. Both firms produce the high-quality good.

Let $\theta_{H}$ be the value of $\theta$ for which the corresponding consumer is indifferent between buying nothing and buying the high-quality good. Then

The direct demand function is

$$
\theta_{H}=\frac{p_{H}}{k_{H}}
$$

$$
q_{H}=1-F\left(\frac{p_{H}}{k_{H}}\right) .
$$

$q_{H}$ denotes the supply of the good of quality $k_{H}$ in the market. We have $0<q_{H}<1$, and

$$
q_{H}=q_{A}+q_{B} .
$$

From equation (4) the inverse demand function is

$$
p_{H}=k_{H} G\left(1-q_{A}-q_{B}\right) .
$$

Since $0<G\left(1-q_{B}\right)<1$, we have $0<p_{H}<k_{H}$.

The profits of Firm A and $B$ are

$$
\begin{gathered}
\pi_{A}=k_{H} G\left(1-q_{A}-q_{B}\right) q_{A}-c\left(q_{A}\right), \\
\pi_{B}=k_{H} G\left(1-q_{A}-q_{B}\right) q_{B}-c\left(q_{B}\right)-L .
\end{gathered}
$$

The first order conditions for profit maximization of Firm A and B are

$$
\begin{aligned}
& \frac{\partial \pi_{A}}{\partial q_{A}}=k_{H} G\left(1-q_{A}-q_{B}\right)-k_{H} G^{\prime}\left(1-q_{A}-q_{B}\right) q_{A}-c^{\prime}=0, \\
& \frac{\partial \pi_{B}}{\partial q_{B}}=k_{H} G\left(1-q_{A}-q_{B}\right)-k_{H} G^{\prime}\left(1-q_{A}-q_{B}\right) q_{B}-c^{\prime}=0 .
\end{aligned}
$$

The second order conditions are

$$
\begin{aligned}
& \frac{\partial^{2} \pi_{A}}{\partial q_{A}^{2}}=-k_{H}\left[2 G^{\prime}\left(1-q_{A}-q_{B}\right)-G^{\prime \prime}\left(1-q_{A}-q_{B}\right) q_{A}\right]-c^{\prime \prime}<0, \\
& \frac{\partial^{2} \pi_{B}}{\partial q_{B}^{2}}=-k_{H}\left[2 G^{\prime}\left(1-q_{A}-q_{B}\right)-G^{\prime \prime}\left(1-q_{A}-q_{B}\right) q_{B}\right]-c^{\prime \prime}<0 .
\end{aligned}
$$


Denote the equilibrium values of the outputs of Firm A and B, the price and the profits of the firms by $q_{A}^{e l}, q_{B}^{e l}, p_{H}^{e l}, \pi_{A}^{e l}$, and $\pi_{B}^{e l}$.Similarly to the previous section, if the negotiation between the foreign firm and the domestic firm about the license fee breaks down, the foreign firm can enter the market of Country B without license. Therefore, the domestic firm must pay the difference between its profit excluding the license fee and its profit in the entry (without license) case. Thus, the license fee is equal to

$$
\left(\pi_{B}^{e l}+L\right)-\pi_{B}^{e}
$$

Denote it by $L^{e l}$. The payoff of the foreign innovating firm is the sum of the license fee and its profit as a firm in the duopoly. It is equal to

$$
L^{e l}+\pi_{A}^{e l}
$$

\subsection{Uniform distribution and linear cost function case}

In the uniform distribution and linear cost function case the equilibrium values of the variables are

$$
\begin{gathered}
q_{A}^{e l}=q_{B}^{e l}=\frac{k_{H}-c}{3 k_{H}}, p_{H}^{e l}=\frac{k_{H}+2 c}{3}, \\
\pi_{A}^{e l}=\frac{\left(k_{H}-c\right)^{2}}{9 k_{H}}, \pi_{B}^{e l}=\frac{\left(k_{H}-c\right)^{2}}{9 k_{H}}-L^{e l} .
\end{gathered}
$$

About the license fee there are the following two cases.

(1) When $k_{L}>\frac{2 c k_{H}}{k_{H}+c}\left(\right.$ or $\left.k_{H}<\frac{C k_{L}}{2 c-k_{L}}\right)$,

$$
\begin{gathered}
L^{e l}=\frac{\left(k_{H}-k_{L}\right)\left(2 c k_{H} k_{L}^{2}-k_{H}^{2} k_{L}^{2}-c^{2} k_{L}^{2}+16 k_{H}^{3} k_{L}+4 c k_{H}^{2} k_{L}+16 c^{2} k_{H} k_{L}-36 c^{2} k_{H}^{2}\right)}{9 k_{H} k_{L}\left(4 k_{H}-k_{L}\right)^{2}} . \\
L^{e l}+\pi_{A}^{e l}=\frac{C}{9 k_{H} k_{L}\left(4 k_{H}-k_{L}\right)^{2}},
\end{gathered}
$$

where

$$
\begin{aligned}
C= & 2 k_{H}^{2} k_{L}^{3}-4 c k_{H} k_{L}^{3}+2 c^{2} k_{L}^{3}-25 k_{H}^{3} k_{L}^{2}+14 c k_{H}^{2} k_{L}^{2}-25 c^{2} k_{H} k_{L}^{2}+32 k_{H}^{4} k_{L} \\
& -28 c k_{H}^{3} k_{L}+68 c^{2} k_{H}^{2} k_{L}-36 c^{2} k_{H}^{3} .
\end{aligned}
$$

(2) When $k_{L} \leq \frac{2 c k_{H}}{k_{H}+c}$ (or $\left.k_{H} \geq \frac{C k_{L}}{2 c-k_{L}}\right)$, since $\pi_{B}^{e}=0$,

$$
L^{e l}+\pi_{A}^{e l}=\frac{2\left(k_{H}-c\right)^{2}}{9 k_{H}} .
$$

\subsection{Uniform distribution and quadratic cost function case}

In the uniform distribution and quadratic cost function case the equilibrium values of the variables are

$$
\begin{gathered}
q_{A}^{e l}=q_{B}^{e l}=\frac{k_{H}}{3 k_{H}+2 c}, p_{H}^{e l}=\frac{k_{H}\left(k_{H}+2 c\right)}{3 k_{H}+2 c}, \\
\pi_{A}^{e l}=\frac{k_{H}^{2}\left(k_{H}+c\right)}{\left(3 k_{H}+2 c\right)^{2}}, \pi_{B}^{e l}=\frac{k_{H}^{2}\left(k_{H}+c\right)}{\left(3 k_{H}+2 c\right)^{2}}-L^{e l}, \\
L^{e l}=\frac{D}{\left(3 k_{H}+2 c\right)^{2}\left(k_{L}^{2}-4 k_{H} k_{L}-4 c k_{L}-4 c k_{H}-4 c^{2}\right)^{2}},
\end{gathered}
$$


and

where

$$
L^{e l}+\pi_{A}^{e}=\frac{E}{\left(3 k_{H}+2 c\right)^{2}\left(k_{L}^{2}-4 k_{H} k_{L}-4 c k_{L}-4 c k_{H}-4 c^{2}\right)^{2}}
$$

$$
\begin{aligned}
D= & \left(k_{H}-k_{L}\right)\left(k_{H} k_{L}+c k_{L}+c k_{H}\right)\left(16 k_{H}^{3} k_{L}-k_{H}^{2} k_{L}^{2}+48 c k_{H}^{2} k_{L}+48 c^{2} k_{H} k_{L}\right. \\
& \left.+16 c^{3} k_{L}+16 c k_{H}^{3}+48 c^{2} k_{H}^{2}+48 c^{3} k_{H}+16 c^{4}\right),
\end{aligned}
$$

and

$$
\begin{aligned}
E= & 2 k_{H}^{3} k_{L}^{4}+2 c k_{H}^{2} k_{L}^{4}-25 k_{H}^{4} k_{L}^{3}-80 c k_{H}^{3} k_{L}^{3}-104 c^{2} k_{H}^{2} k_{L}^{3}-64 c^{3} k_{H} k_{L}^{3} \\
& -16 c^{4} k_{L}^{3}+32 k_{H}^{5} k_{L}^{2}+71 c k_{H}^{4} k_{L}^{2}+16 c^{2} k_{H}^{3} k_{L}^{2}-72 c^{3} k_{H}^{2} k_{L}^{2}-64 c^{4} k_{H} k_{L}^{2} \\
& -16 c^{5} k_{L}^{2}+64 c k_{H}^{5} k_{L}+192 c^{2} k_{H}^{4} k_{L}+192 c^{3} k_{H}^{3} k_{L}+64 c^{4} k_{H}^{2} k_{L}+32 c^{2} k_{H}^{5} \\
& +96 c^{3} k_{H}^{4}+96 c^{4} k_{H}^{3}+32 c^{5} k_{H}^{2} .
\end{aligned}
$$

\section{The optimum strategy for the foreign innovator}

To obtain the optimum strategy for the foreign innovating firm let us compare the profit of Firm A when it licenses its technology to Firm B without entry and its profit when it enters the market of Country B with license to Firm B. The difference between them is

$$
L^{l}-\left(L^{e l}+\pi_{A}^{e l}\right) \text {. }
$$

Similarly, the difference between its profit when it licenses its technology to Firm B without entry and its profit when it enters the market of Country B without license, and the difference between its profit when it enters the market of Country B with license to Firm B and its profit when it enters the market of Country B without license are

$$
L^{l}-\pi_{A}^{e}
$$

and

$$
\left(L^{e l}+\pi_{A}^{e l}\right)-\pi_{A}^{e}
$$

For example, if both of $L^{l}-\left(L^{e l}+\pi_{A}^{e l}\right)$ and $L^{l}+\pi_{A}^{e}$ are positive, license only (without entry) strategy is the optimum strategy.

We consider two specific cases.

\subsection{Uniform distribution and linear cost function case}

There are two cases.

(1) When $k_{L}>\frac{2 c k_{H}}{k_{H}+c}\left(\right.$ or $\left.k_{H}<\frac{C k_{L}}{2 c-k_{L}}\right)$, we have

$$
L^{l}-\left(L^{e l}+\pi_{A}^{e l}\right)=\frac{\left(k_{H}-c\right)^{2}}{36 k_{H}}>0 .
$$

Thus, license only strategy is more beneficial than entry with license strategy for the foreign innovating firm. Also we have

$$
L^{l}-\pi_{A}^{e}=\frac{\left[k_{L}\left(k_{H}+c\right)-2 c k_{H}\right]\left(4 k_{H}^{2} k_{L}-10 c k_{H} k_{L}+8 c k_{H}^{2}-3 k_{H} k_{L}^{2}+c k_{L}^{2}\right)}{4 k_{H} k_{L}\left(4 k_{H}-k_{L}\right)^{2}} .
$$

The denominator is positive, and $k_{L}\left(k_{H}+c\right)-2 c k_{H}>0$. Let

$$
\lambda=4 k_{H}^{2} k_{L}-10 c k_{H} k_{L}+8 c k_{H}^{2}-3 k_{H} k_{L}^{2}+c k_{L}^{2} .
$$

When $k_{H}=k_{L}, \lambda=k_{L}{ }^{3}-c k_{L}^{2}>0$ and 


$$
\frac{d \lambda}{d k_{H}}=8 k_{H} k_{L}-10 c k_{L}+16 c k_{H}-3 k_{L}^{2}>0 .
$$

Since $k_{H}>k_{L}$, we have $L^{l}>\pi_{A}^{e}$. Therefore, license only strategy is the optimum strategy for the foreign innovating firm.

(2) When $k_{L} \leq \frac{2 c k_{H}}{k_{H}+c}\left(\right.$ or $k_{H} \geq \frac{C k_{L}}{2 c-k_{L}}$ ), we have

$$
L^{l}-\left(L^{e l}+\pi_{A}^{e l}\right)=\frac{\left(k_{H}-c\right)^{2}}{36 k_{H}}>0, L^{l}-\pi_{A}^{e}=0 .
$$

Thus, both of license only strategy and entry without license strategy are the optimum strategies for the foreign innovating firm.

Summarizing the results;

Proposition 1. In the uniform distribution and linear cost function case;

1. If $k_{L}$ is sufficiently large, the license only (without entry) strategy is the optimum strategy for the foreign innovating firm.

2. If $k_{L}$ is small, both of the license only strategy and the entry only (without license) strategy are the optimum strategies.

\subsection{Uniform distribution and quadratic cost function case}

In the uniform distribution and quadratic cost function case we have

$$
L^{l}-\left(L^{e l}+\pi_{A}^{e l}\right)=\frac{k_{H}^{2}\left(k_{H}^{2}-4 c k_{H}-4 c^{2}\right)}{4\left(k_{H}+c\right)\left(3 k_{H}+2 c\right)^{2}} .
$$

When $k_{H}>2(\sqrt{2}+1) c$, it is positive; and when $k_{H}<2(\sqrt{2}+1) c$, it is negative. Thus, when $k_{H}$ is relatively large to $c$, license only strategy is more beneficial than license with entry strategy for the foreign innovating firm; when $k_{H}$ is small, entry with license strategy is more beneficial.

Also we have

where

$$
\begin{gathered}
L^{l}-\pi_{A}^{e}=\frac{k_{L}^{2}\left(k_{H}+2 c\right) \varphi}{4\left(k_{H}+c\right)\left(4 k_{H} k_{L}+4 c k_{L}+4 c k_{H}+4 c^{2}-k_{L}^{2}\right)^{2}}, \\
\left(L^{e l}+\pi_{A}^{e l}\right)-\pi_{A}^{e}=\frac{\left(k_{H}-k_{L}\right)\left(k_{H} k_{L}+c k_{L}+c k_{H}\right) \psi}{\left(3 k_{H}-2 c\right)^{2}\left(k_{L}^{2}+4 k_{H} k_{L}+4 c k_{L}+4 c k_{H}+4 c^{2}\right)^{2}},
\end{gathered}
$$

$$
\begin{gathered}
\varphi=4 k_{H}^{2} k_{L}-3 k_{H} k_{L}^{2}-2 c k_{L}^{2}-4 c k_{H} k_{L}-8 c^{2} k_{L}+4 c k_{H}^{2}-4 c^{2} k_{H}-8 c^{3}, \\
\psi=7 k_{H}^{2} k_{L}^{2}+12 c k_{H} k_{L}^{2}+4 c^{2} k_{L}^{2}-4 k_{H}^{3} k_{L}+12 c k_{H}^{2} k_{L}+32 c^{2} k_{H} k_{L}+16 c^{3} k_{L}-4 c k_{H}^{3} \\
+12 c^{2} k_{H}^{2}+32 c^{3} k_{H}+16 c^{4} .
\end{gathered}
$$

Since $k_{H}>k_{L}$, we see that $k_{L}^{2}\left(k_{H}+2 c\right)>0,\left(k_{H}-k_{L}\right)\left(k_{H} k_{L}+c k_{L}+c k_{H}\right)>0$ and the denominators of them are positive. About $\varphi$ and $\psi$ we find

$$
k_{H} \varphi+\psi=2\left(k_{H}+2 c\right)\left(2 k_{H} k_{L}^{2}+c k_{L}^{2}+4 c k_{H} k_{L}+4 c^{2} k_{L}+4 c^{2} k_{H}+4 c^{3}\right)>0 .
$$

Thus, at least one of $\varphi$ and $\psi$ is positive, and hence at least one of $L^{l}-\pi_{A}^{e}$ and $\left(L^{e l}+\pi_{A}^{e l}\right)-$ $\pi_{A}^{e}$ is positive. Therefore, entry without license strategy never be the optimum strategy.

Summarizing the results;

Proposition 2. In the uniform distribution and quadratic cost function case;

1. If $k_{H}$ is sufficiently large (or $c$ is small), license only strategy is the optimum strategies 
for the foreign innovating firm.

2. If $k_{H}$ is small, entry with license strategy is the optimum strategy.

The reason for the difference between proposition 1 and 2 is as follows. The profit of the foreign innovating firm under license only strategy is

$$
\pi_{B}^{l}+L^{l}-\pi_{B}^{e}
$$

And the profit of the foreign innovating firm under entry with license strategy is

So the difference between two strategies is

$$
\pi_{A}^{e l}+\pi_{B}^{e l}+L^{e l}-\pi_{B}^{e} \text {. }
$$

$$
\pi_{B}^{l}+L^{l}-\pi_{A}^{e l}+\pi_{B}^{e l}+L^{e l}
$$

$\pi_{B}^{l}+L^{l}$ is monopoly profit with the high-quality good and $\pi_{A}^{e l}+\pi_{B}^{e l}+L^{e l}$ is total profit under duopoly where both firms produce the high-quality good. Therefore, when monopoly profit is larger (smaller) than total profit under duopoly, license only strategy is more profitable (unprofitable) than entry with license strategy.

In the linear cost functions case, monopoly profit always bigger than total profit under duopoly so the foreign innovating firm uses license only strategy. If the domestic firm is weak and drops out when the foreign innovating firm enters the domestic market, license only strategy and entry only strategy become optimal (proposition 1-2). The foreign innovating firm always gets monopoly profit.

On the other hand, in the quadratic cost functions case, total profit under duopoly may become larger than monopoly profit so the foreign innovating firm uses entry with license strategy (proposition 2-2). In this case, marginal cost becomes large as production becomes large, so the foreign innovating firm enters the domestic market and produce with small marginal cost although the market becomes more competitive. But when $c$ is small (or $k_{H}$ is large), the result approaches to the result under linear cost functions, so license only strategy is optimal like proposition 1 .

\section{A note on extension to endogenous quality model}

Nguyen (2014) and Nguyen, Sgro and Nabin (2014) presented models of vertical product differentiation with endogenous quality choice by firms. In particular, Nguyen, Sgro and Nabin (2014) analyzed a licensing problem in a duopoly with a foreign innovating firm which has a new technology to produce a higher quality good.

Our analysis can be extended to a case of endogenous quality choice. For example, let us consider the entry without license case. Assume uniform distribution of consumers' taste parameter. Suppose that Firm A produces a good of quality $k_{A}$, and Firm B produces a good of quality $k_{B} . k_{A}>k_{B}$. Let $\theta_{B}$ be the value of $\theta$ for which the corresponding consumer is indifferent between buying nothing and buying Firm B's good. Then, $\theta_{B}=p_{B} / k_{B}$. Let $\theta_{A}$ be the value of $\theta$ for which the corresponding consumer is indifferent between buying Firm A's good and Firm B's good. Then, $\theta_{B}=\left(p_{A}-p_{B}\right) /\left(k_{A}-k_{B}\right) \cdot p_{A}$ and $p_{B}$ are the prices of the goods. Assume that the constant marginal cost of Firm A is $0.5 k_{A}{ }^{2}$, and that of Firm B is $k_{B}{ }^{2}$. Let $q_{A}$ and $q_{B}$ be the outputs of Firm $\mathrm{A}$ and $\mathrm{B}$. Then, the inverse demand functions are written as follows.

$$
p_{A}=\left(k_{A}-k_{B}\right)\left(1-q_{A}\right)+k_{B}\left(1-q_{A}-q_{B}\right), p_{B}=k_{B}\left(1-q_{A}-q_{B}\right) .
$$

The profits of Firm A and B are

$$
\pi_{A}=\left[\left(k_{A}-k_{B}\right)\left(1-q_{A}\right)+k_{B}\left(1-q_{A}-q_{B}\right)\right] q_{A}-\frac{1}{2} k_{A}^{2} q_{A}, \pi_{B}=k_{B}\left(1-q_{A}-q_{B}\right) q_{B}-k_{B}^{2} q_{B} .
$$


The first order conditions for profit maximization of Firm A and B with respect to the outputs are

and

$$
\left(k_{A}-k_{B}\right)\left(1-q_{A}\right)+k_{B}\left(1-q_{A}-q_{B}\right)-k_{A} q_{A}-\frac{1}{2} k_{A}^{2}=0,
$$

$$
k_{B}\left(1-q_{A}-q_{B}\right)-k_{B} q_{B}-k_{B}^{2}=0 .
$$

The equilibrium outputs of the goods and the profits of the firms are

$$
\begin{gathered}
q_{A}=\frac{2 k_{A}-k_{B}-k_{A}^{2}+k_{B}^{2}}{4 k_{A}-k_{B}}, q_{B}=\frac{k_{A}\left(2+k_{A}-4 k_{B}\right)}{2\left(4 k_{A}-k_{B}\right)}, \\
\pi_{A}=\frac{k_{A}\left(2 k_{A}-k_{B}-k_{A}^{2}+k_{B}^{2}\right)^{2}}{\left(4 k_{A}-k_{B}\right)^{2}}, \pi_{B}=\frac{k_{A}^{2} k_{B}\left(2+k_{A}-4 k_{B}\right)^{2}}{4\left(4 k_{A}-k_{B}\right)^{2}} .
\end{gathered}
$$

Given these equilibrium profits the firms choose their quality. The conditions for profit maximization with respect to the quality are

for Firm A, and

$$
k_{B}^{3}+4 k_{A} k_{B}^{2}-k_{B}^{2}-5 k_{A}^{2} k_{B}+2 k_{A} k_{B}+12 k_{A}^{3}-8 k_{A}^{2}=0,
$$

$$
4 k_{B}^{2}-47 k_{A} k_{B}+2 k_{B}+4 k_{A}^{2}+8 k_{A}=0,
$$

for Firm B. The firms choose the following quality

$$
k_{A} \approx 0.6882, k_{B} \approx 0.2523 \text {. }
$$

The full analyses using the model of endogenous quality choice are future challenges.

\section{Concluding remark}

We have analyzed a choice of the foreign innovating firm to license its technology for producing the high quality good to a domestic firm or to enter the market, which is monopolistic, of the domestic country, with or without license. We have shown that the relative benefit of license and entry depends on the form of cost functions.

In the future research we want to study the problem in oligopoly, and public policy by the government of the domestic country to promote or prevent license or entry by the foreign firm. As we mentioned in the previous section, our analysis can be extended to a case of endogenous quality choice ${ }^{1}$.

Acknowledgements. This work was supported by JSPS KAKENHI Grant Number (15K03481).We thank the referee for his/her thorough review and highly appreciate the comments, and suggestions which significantly contributed to improving the quality of the paper.

\section{References}

Boone, J. (2001) Intensity of competition and the incentive to innovate, International Journal of Industrial Organization, 19, 705-726.

Bonanno, G. and Haworth, B. (1998) Intensity of competition and the choice between product and process innovations, International Journal of Industrial Organization, 16, 495-510.

\footnotetext{
${ }^{1}$ In the model of Nguyen, Sgro and Nabin (2014) the quality of the good produced by the new superior technology is fixed to be 1 , and a firm, which does not buy a license, chooses the quality of its good between 0 and 1 .
} 
Elberfeld, W. and Nti, K. O. (2004) Oligopolistic competition and new technology adoption under uncertainty, Journal of Economics, 82, 105-121.

Filippini, L. (2005) Licensing contract in a Stackelberg model, The Manchester School, 73, 582-598.

Hattori, M. and Y. Tanaka (2014) Incentive for adoption of new technology in duopoly under absolute and relative profit maximization, Economics Bulletin, 34. 2051-2059.

Hattori, M. and Tanaka, Y. (2015) Subsidy or tax policy for new technology adoption in duopoly with quadratic and linear cost functions, Economics Bulletin, 35, 1423-1433.

Kabiraj, T. (2004) Patent licensing in a leadership structure, The Manchester School, 72, 188205.

Kamien, T. and Tauman, Y. (1986) Fees versus royalties and the private value of a patent, Quarterly Journal of Economics, 101, 471-492.

Katz, M. and Shapiro, C. (1985) On the licensing of innovations, Rand Journal of Economics, $16,504-520$.

La Manna M. (1993) Asymmetric Oligopoly and Technology Transfers, Economic Journal, $103,436-443$.

Matsumura, T., Matsushima, N. and Cato, S. (2013) Competitiveness and R\&D competition revisited, Economic modelling, 31, 541-547.

Mussa, M. and Rosen, S. (1978) Monopoly and product quality, Journal of Economic Theory, 18, 130-156, 1978.

Nguyen, X. (2014) Monopolistic third-degree price discrimination under vertical product differentiation, Economics Letters, 125, 153-155.

Nguyen, X, Sgro, P. and Nabin, N. (2014) Licensing under vertical product differentiation: Price vs. quantity competition, Economic Modelling, 36, 600-606.

Pal, R. (2010) Technology adoption in a differentiated duopoly: Cournot versus Bertrand, Research in Economics, 64, 128-136.

Rebolledo, M. and J. Sandonís (2012) The effectiveness of R\&D subsidies, Economics of Innovation and New Technology, 21, 815-825.

Sen, D. and Tauman, Y. (2007) "General licensing schemes for a cost-reducing Innovation", Games and Economic Behavior, 59, 163-186.

Tanaka, Y. (2001) "Profitability of price and quantity strategies in a duopoly with vertical product differentiation", Economic Theory, 17, 693-700.

Wang, X. H. and Yang, B. Z. (2004) On technology licensing in a Stackelberg duopoly, Australian Economic Papers, 43, 448-458.

Watanabe N. and Muto, S. (2008) Stable profit sharing in a patent licensing game: general bargaining outcomes, International Journal of Game Theory, 37, 505-523.

Zhang, Y., Mei, S. and Zhong, W. (2014) New technology adoption in a Cournot oligopoly with spillovers, Journal of Economics, 112, 115-136. 